\title{
Design of Active Frequency Selective Surface with Curved Composite Structures and Tunable Frequency Response
}

\author{
In-Gon Lee, ${ }^{1}$ Yong Bae Park, ${ }^{2}$ Heung-Jae Chun, ${ }^{3}$ Yoon-Jae Kim, ${ }^{4}$ and Ic-Pyo Hong1 \\ ${ }^{1}$ Department of Information and Communication Engineering, Kongju National University, Cheonan 31080, Republic of Korea \\ ${ }^{2}$ Department of Electrical and Computer Engineering, Ajou University, Suwon, Republic of Korea \\ ${ }^{3}$ Department of Mechanical Engineering, Yonsei University, Seoul, Republic of Korea \\ ${ }^{4}$ Agency for Defense Development, Daejeon, Republic of Korea
}

Correspondence should be addressed to Ic-Pyo Hong; iphong@kongju.ac.kr

Received 25 June 2017; Accepted 27 September 2017; Published 9 November 2017

Academic Editor: Muhammad Ramlee Kamarudin

Copyright (c) 2017 In-Gon Lee et al. This is an open access article distributed under the Creative Commons Attribution License, which permits unrestricted use, distribution, and reproduction in any medium, provided the original work is properly cited.

\begin{abstract}
We present an active frequency selective surface (AFSS) consisting of a curved composite structure that provides structural stability and robustness. The proposed structure can operate on either the C-band (OFF state) or X-band (ON state) by controlling the PIN diode located between the cross-shaped loop and the inductive stub on the surface. Moreover, it minimizes parasitic couplings through grid-type on/off bias circuits and via holes. Thus, the AFSS guarantees isolation from the unit cell, which is a downside of a previous control technique called reconfigurable frequency selective surface. We analyzed the impact of composite structures and the three-dimensional shape on the AFSS transmission with a foam-core sandwich structure, which is light and mechanically strong, by considering conditions of a real application environment.
\end{abstract}

\section{Introduction}

A frequency selective surface (FSS) is an electromagnetic structure that resonates with a specific frequency, exhibiting a corresponding impedance derived from its capacitance and inductance, and it selectively transmits or reflects the frequency of incident electromagnetic waves [1]. FSSs are currently being applied, for instance, to reduce interference in electronic devices [2] and miniaturize radar cross sections [3]. However, conventional FSSs present a limitation when applied to modern multifunctional and complex systems, as they constitute a passive circuit operating on a single frequency band. To address this problem, researchers have developed the active FSS (AFSS), which can operate on different frequency bands $[4,5]$.

AFSSs include adjustable elements within their unit cell to vary the equivalent capacitance and inductance. Therefore, they can have various characteristics including resonance frequencies ranging from megahertz to terahertz, adjustable bandwidth, and frequency attenuation based on the control of the operating frequency. The active circuit control to change the frequency response can include elements such as PIN diodes, varactor diodes, radio-frequency (RF) microelectromechanical systems, and other electronic control elements that directly modify the unit cell impedance. There is extensive research on AFSS control using these elements given its ease of construction [6-13]. However, the resulting AFSSs require many active elements to provide a stable frequency response, and they are affected by aspects such as incidence angle and polarization, which complicate the circuit structure $[7,8,13]$. Moreover, a typical AFSS requires, for instance, each of its unit cells to be isolated from the bias circuit and the surrounding unit cells, as well as several RF chokes [1113]. Therefore, many studies focus only on improving the electric characteristics related to the flat dielectric substrate without considering the impedance or incidence angle [813]. Nevertheless, more research is needed on designs that employ curved-foam or composite structures and take into consideration the application, operation, and performance under real environmental conditions [6-13]. Although some studies have been conducted for FSS based on composite materials or three-dimensional structures, they were limited to passive and impractical structure $[14,15]$. 
For this study, we used a flexible printed circuit board, which is very thin and malleable and thus can be used to construct either curved or flat structures. In addition, we employed a commercial PIN diode that provides simple activation and deactivation. Using these elements, we designed a four-legged loaded AFSS structure for transmission in either the $\mathrm{X}$ - or C-bands, depending on its state, $\mathrm{ON}$ or OFF, respectively. This structure gained impedance and stability with respect to the incidence angle and distance between the unit cell and bias circuits given its composition, which includes the diode, symmetric, and bias circuits, for a grid-type power supply. Based on the proposed design, we fabricated the structure with a single-curvature and fiberreinforced composite materials, which are strong, dense, and feature high modulus, dimensional stability, and less fatigue [16-18]. To verify the design results, we analyzed the impact of the dielectric properties and curvature radius of the composite materials through electromagnetic transmission measurements.

\section{AFSS Design and Simulation}

The proposed structure has a four-legged loaded element pattern on the dielectric substrate, which is known to have a stable frequency response according to the incidence angle of the incident and polarized waves, a via hole connected to its bottom face, which is used for the diode power supply, and a function to reconfigure the operating frequency depending on the PIN diode located between the cross-shaped loop and the Pi-shaped slot stub. In general, an AFSS needs additional circuits, an RF choke, or resistors coupled to the bias circuits to control plane waves. However, we designed a grid-type bias circuit along with the via hole, and by using the resulting resistance and inductance, the proposed AFSS guaranteed adequate isolation between the unit cell and bias circuit and minimized the possibility of a parasitic effect $[5,17]$. For this study, we considered the MADP-000907-14020 PIN diode manufactured by MACOM, which can be switched on and off in the X-band. The PIN diode model is shown in Figure 1(b), and its parameters along with those of the circuit illustrated in Figure 1(a) are listed in Table 1. We included a via hole with radius of $0.3 \mathrm{~mm}$ and considered the dielectric substrate as a polyimide film with a thickness of $0.2 \mathrm{~mm}$, a dielectric constant $\left(\varepsilon_{r}\right)$ of 3.5 , and a loss tangent $(\tan \delta)$ of 0.004 .

We analyzed the structure using the Floquet mode of the ANSYS HFSS software, which simulates wave propagation and transmission loss according to frequency. This analysis was performed on the diode considering the case when the PIN diode is in short circuit and on the equivalent circuit when the diode is in the ON state. From this analysis, we determined the parameters that affect the frequency response of the proposed AFSS and obtained their optimized factors, which are listed in Table 1.

To verify the transmission loss according to frequency in the AFSS structure, we thoroughly examined the frequency response for varying incidence angles of $0^{\circ}, 30^{\circ}$, and $60^{\circ}$ for the TE and TM modes, which are different when the PIN diode is in short circuit and in the ON state. The corresponding results are shown in Figure 2(a). In addition,
TABLE 1: AFSS dimensions and PIN diode parameters.

\begin{tabular}{lcc}
\hline Classification & Parameter & Value \\
\hline & $L_{1}$ & 8.2 \\
& $L_{2}$ & 6.9 \\
& $L_{3}$ & 6.9 \\
Dimensions $(\mathrm{mm})$ & $L_{4}$ & 3.6 \\
& $L_{5}$ & 2.3 \\
& $W_{1}$ & 0.5 \\
$W_{2}$ & 0.25 \\
& $W_{3}$ & 0.4 \\
\hline \multirow{3}{*}{ PIN diode } & $L_{D}$ & $0.15 \mathrm{uH}$ \\
& $C_{R}$ & $0.05 \mathrm{pF}$ \\
& $R_{F}$ & $4 \Omega$ \\
& $R_{R}$ & $20 \mathrm{k} \Omega$ \\
\hline
\end{tabular}

we analyzed the length variation of the Pi-shaped slot stub, $L_{5}$, as it controls the operating frequency depending on the PIN diode state. The corresponding results for transmission loss are shown in Figure 2(b). From these results, we determined a resonance frequency of $9.79 \mathrm{GHz}$ at $-3 \mathrm{~dB}$ with a bandwidth of $1.41 \mathrm{GHz}$ when the diode is in short circuit and another of $5.72 \mathrm{GHz}$ at $-3 \mathrm{~dB}$ with a bandwidth of $1.54 \mathrm{GHz}$ when the diode is in the $\mathrm{ON}$ state. This indicates an approximate variation of $4.07 \mathrm{GHz}$ between the C- and Xbands. Furthermore, the results show a stable response for the angles of incident and polarized waves varying between $0^{\circ}$ and $60^{\circ}$.

We also evaluated the electromagnetic field and its distribution on the surface of the proposed structure to determine its operational mechanism. The results for the two resonance frequencies (i.e., $9.79 \mathrm{GHz}$ and $5.72 \mathrm{GHz}$ ) according to the diode state (i.e., ON or OFF) are shown in Figures 3(a)-3(d). When the diode is $\mathrm{ON}$, there is a strong electromagnetic field (Figure 3(a)) given the capacitance created by the crossshaped loop and the symmetrical current path shown in Figure 3(c), which produces resonance at the higher frequency (i.e., X-band). When the diode is OFF (Figure 3(b)), the structure effect extends beyond the diode and creates a longer current path at a wider ranged capacitance than when the diode is ON, as shown in Figure 3(d). In this case, there is resonance at the lower frequency (i.e., C-band) along the Pi-shaped slot stub.

These results were useful to identify that when the diode is OFF, parameter $L_{1}$ of the unit cell influences the resonance frequency of the X-band, whereas when the diode is $\mathrm{ON}$, parameter $L_{5}$ influences the resonance frequency of the Cband. In addition, to assess the variation in the operating frequency when the diode is $\mathrm{ON}$, we analyzed the frequency variation according to $L_{5}$, and the corresponding results are listed in Table 2.

As the length of $L_{5}$ increases from $0.6 \mathrm{~mm}$ to $2.2 \mathrm{~mm}$, the operating frequency varies from $6.79 \mathrm{GHz}$ to $5.73 \mathrm{GHz}$ when the diode is OFF, and the AFSS provides an isolation of at least $10 \mathrm{~dB}$ between the two bands. Hence, the proposed structure allows easy modification of the operating frequency 


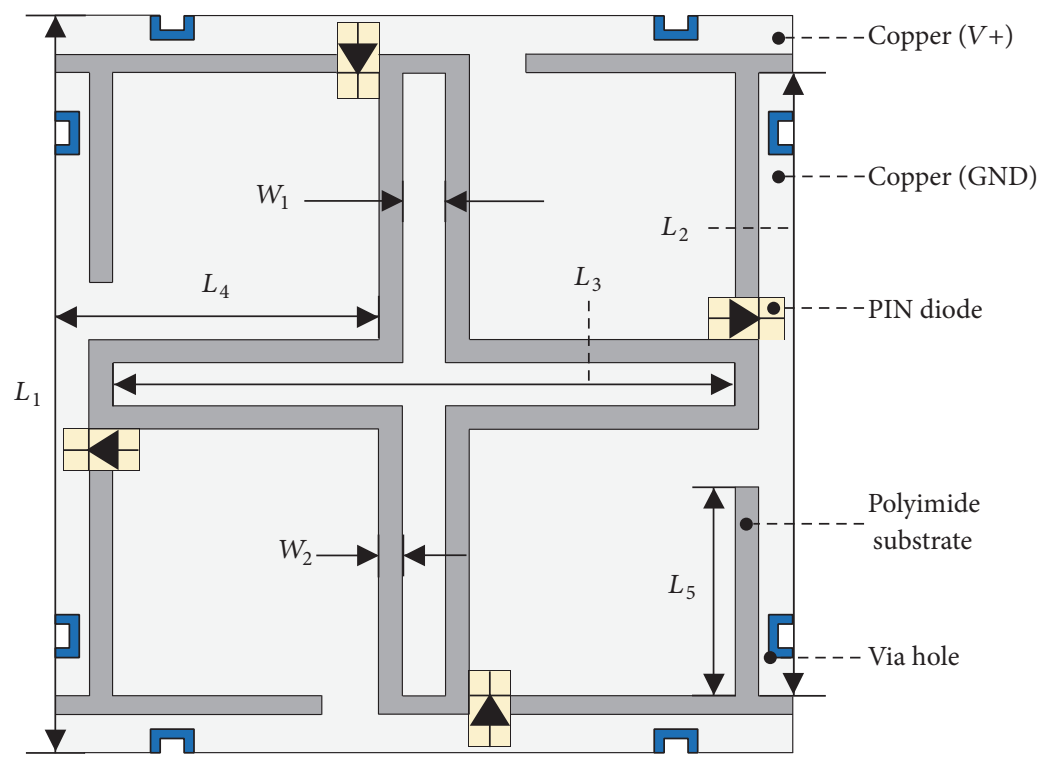

(a) Top view

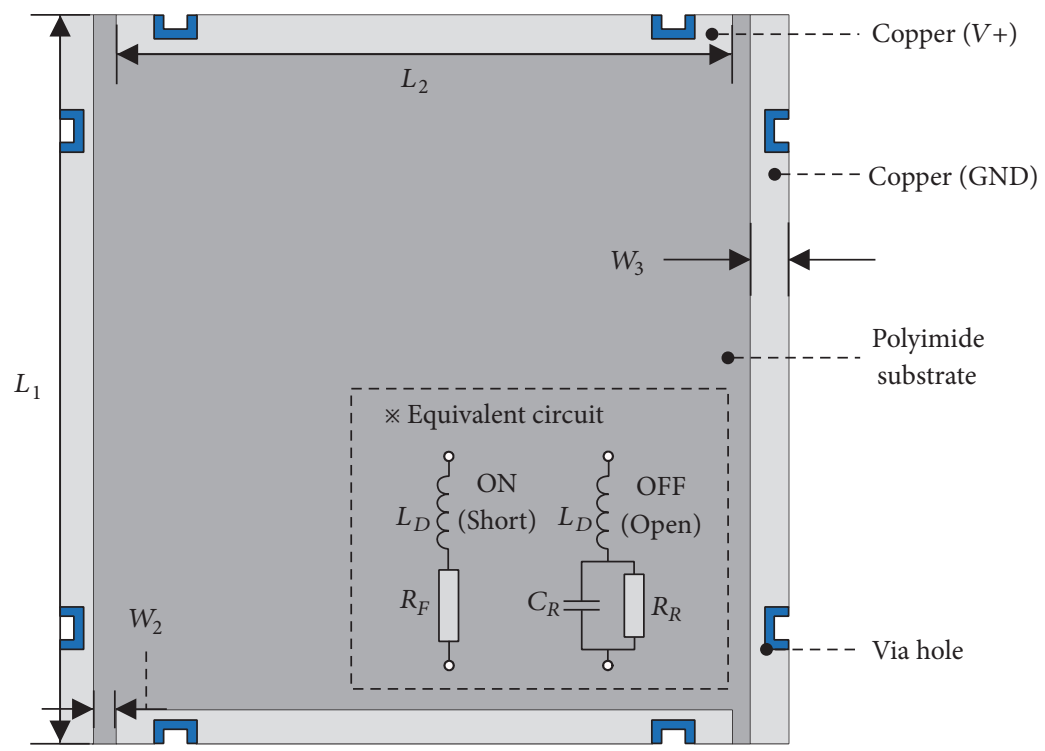

(b) Bottom view with PIN diode model

FIGURE 1: Unit cell of the proposed AFSS.

TABLE 2: Transmission characteristics for variation of parameter $L_{5}$.

\begin{tabular}{lcccc}
\hline$L_{5}(\mathrm{~mm})$ & $f_{\text {ON }}(\mathrm{GHz})$ & $f_{\text {OFF }}(\mathrm{GHz})$ & $f_{\text {offset }}(\mathrm{GHz})$ & $\begin{array}{c}\text { Isolation } \\
f_{\text {ON }}-f_{\text {OFF }}(\mathrm{dB})\end{array}$ \\
\hline 0.6 & 9.80 & 6.79 & 3.01 & 10.41 \\
1.0 & 9.82 & 6.48 & 3.34 & 12.50 \\
1.4 & 9.83 & 6.22 & 3.61 & 15.45 \\
1.8 & 9.84 & 5.94 & 3.90 & 20.75 \\
2.2 & 9.85 & 5.73 & 4.12 & 33.10 \\
\hline
\end{tabular}

bandwidth between $3.01 \mathrm{GHz}$ and $4.12 \mathrm{GHz}$ by adjusting parameter $L_{5}$.
Based on the abovementioned results, we can compare the performance and features of the proposed AFSS with those of related studies, as listed in Table 3. As mentioned in Section 1, most studies do not consider the angle of polarized and incident waves, and they guarantee isolation of the bias circuit by either using complex circuits or adding several elements. In this study, we designed the AFSS structure with a single and grid-type parallel circuit along with a via hole. Consequently, we achieved a variable operational frequency based on simple bias circuits, which do not require additional elements for improved isolation and stability regarding polarization (TE and TM modes) and angle $\left(0^{\circ}\right.$ to $\left.30^{\circ}\right)$ of incident waves. Therefore, we addressed some shortcomings of related studies. 
TABLE 3: Comparison between the proposed AFSS and related studies.

\begin{tabular}{|c|c|c|c|c|c|}
\hline \multirow{2}{*}{ Study } & \multirow{2}{*}{ Technique } & \multirow{2}{*}{ Bias circuit configuration } & \multirow{2}{*}{ Operating freq. (GHz) } & \multicolumn{2}{|c|}{ Stability } \\
\hline & & & & Polarization & Angle \\
\hline [7] & PIN diode & Two-inductor bias & $2.5-5.0$ & TE and TM & $0-45^{\circ}$ \\
\hline [8] & Varactor & Bias grid with inductive pad & $8.0-10.0$ & $\mathrm{TE}$ & $0-45^{\circ}$ \\
\hline [9] & PIN diode & Two-inductor bias & $1.8-2.5$ & $\mathrm{TE}$ & - \\
\hline$[10]$ & PIN diode & One parallel bias & $10.0-12.0$ & $\mathrm{TE}$ & - \\
\hline [11] & PIN diode & $\begin{array}{c}\text { One series bias with } 3 \\
\text { inductors, } 1 \text { resistor }\end{array}$ & $4.0-8.0$ & $\mathrm{TE}$ & - \\
\hline$[12]$ & PIN diode & One parallel bias & $1.0-12.0$ & $\mathrm{TE}$ & - \\
\hline$[13]$ & PIN diode & $\begin{array}{c}\text { One series bias with } 3 \\
\text { inductors }\end{array}$ & $1.5-8.0$ & $\mathrm{TE}$ & $0-45^{\circ}$ \\
\hline This study & PIN diode & One parallel bias & $5.7-9.8$ & TE and TM & $0-30^{\circ}$ \\
\hline
\end{tabular}

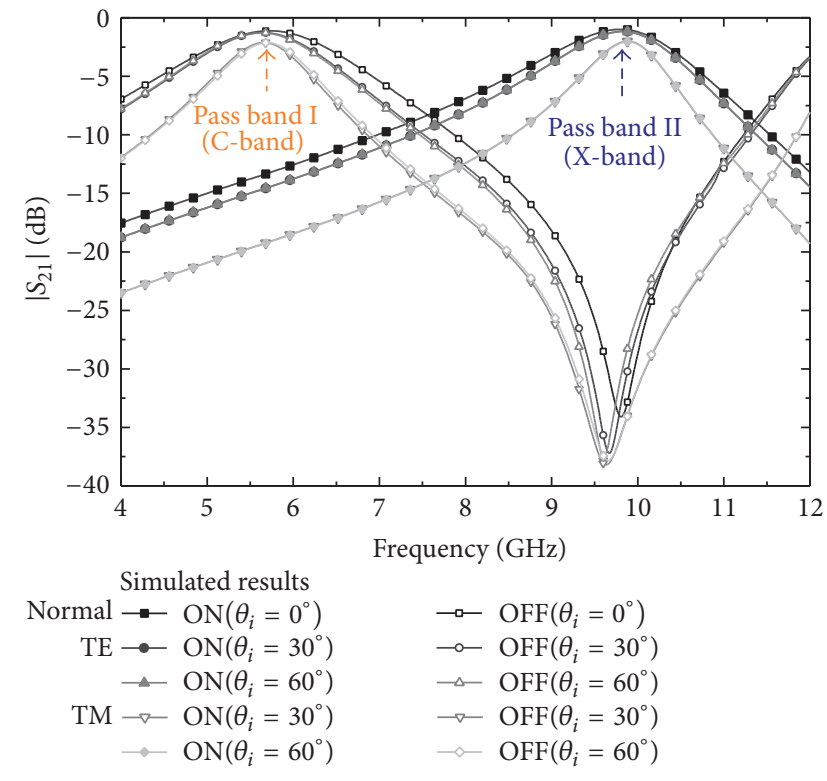

(a) TE and TM mode

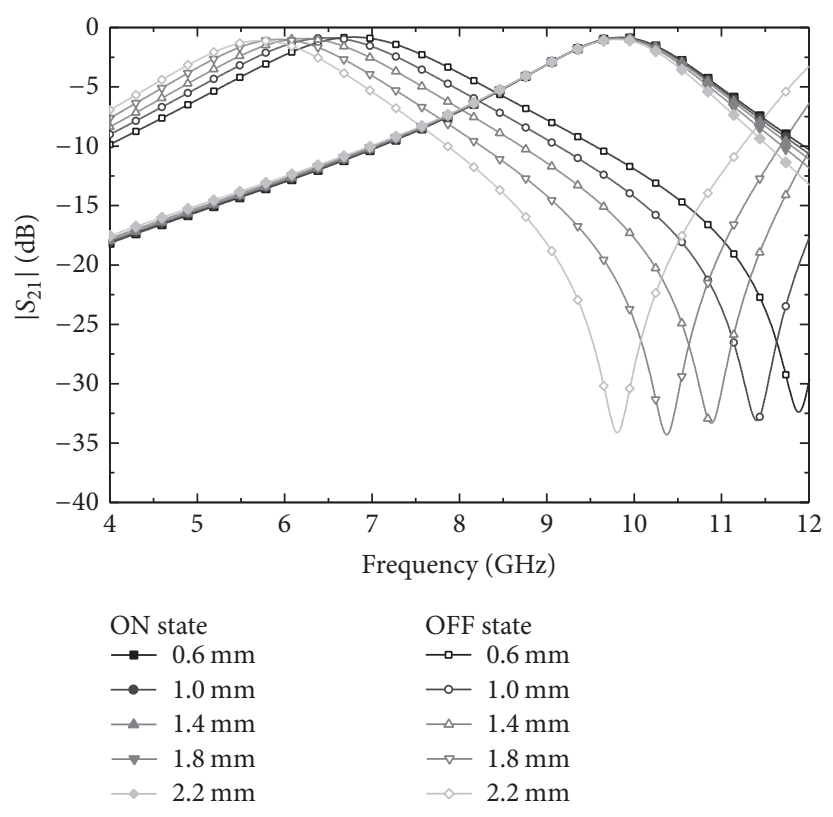

(b) Parametric analysis

FIgURE 2: Transmission characteristics from AFSS simulation.

To verify the performance of the proposed structure, we fabricated an AFSS of $91.4 \mathrm{~mm} \times 91.4 \mathrm{~mm}$ composed of an array having $7 \times 7$ unit cells and using a flexible printed circuit board. The AFSS structure is shown in Figure 4(a), and the bias circuit for the diode operation is shown in Figure 4(b). For the AFSS, we used an ATFC-0402-1N3 inductor of $1.3 \mathrm{nH}$ manufactured by Abracon, with a self-resonance frequency of $10 \mathrm{GHz}$, to prevent noise from the DC input power terminal. Each of the diodes we employed has a minimum voltage of $1.4 \mathrm{~V}$ and maximum current of $20 \mathrm{~mA}$, and its resistance is maximum at $0.75 \mathrm{~W}$. By employing the free-space method in the frequency interval from $8 \mathrm{GHz}$ to $12.5 \mathrm{GHz}$, we obtained the transmission characteristics at incidence angles of $0^{\circ}$ and $30^{\circ}$, as shown in Figure 4(c).

For vertically incident plane waves, the operating frequency has a $-0.59 \mathrm{~dB}$ transmission loss at $9.46 \mathrm{GHz}$ when the diode is OFF (simulation values: $-0.99 \mathrm{~dB}$ at $9.80 \mathrm{GHz}$ ), and at a bandwidth of $2.08 \mathrm{GHz}$ (simulation value: $1.41 \mathrm{GHz}$ ) at $-3 \mathrm{~dB}$, the transmission loss was $-31.55 \mathrm{~dB}$ when the diode was $\mathrm{ON}$, thus leaving an isolation gap of $30.96 \mathrm{~dB}$ (simulation value: $33.1 \mathrm{~dB}$ ). Related studies reported a high isolation from $5 \mathrm{~dB}$ to $25 \mathrm{~dB}$ and a high transmission loss from $-1 \mathrm{~dB}$ to $-10 \mathrm{~dB}$ between the reconfigured operating frequencies, because the corresponding FSSs controlled more than two diodes. Hence, we confirmed that the proposed structure has an improved operation in aspects such as high isolation and low transmission loss, if compared to the studies in [6-8].

\section{Composite Material Fabrication and Curved Structure Evaluation}

FSS structures are being actively studied for use in applications related to RF interference, noise reduction [19], 

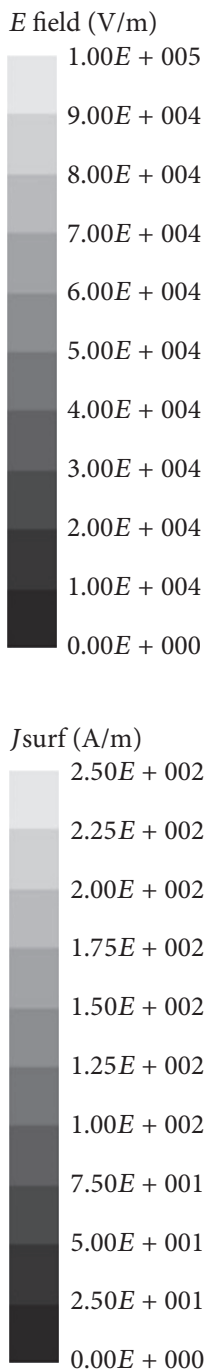

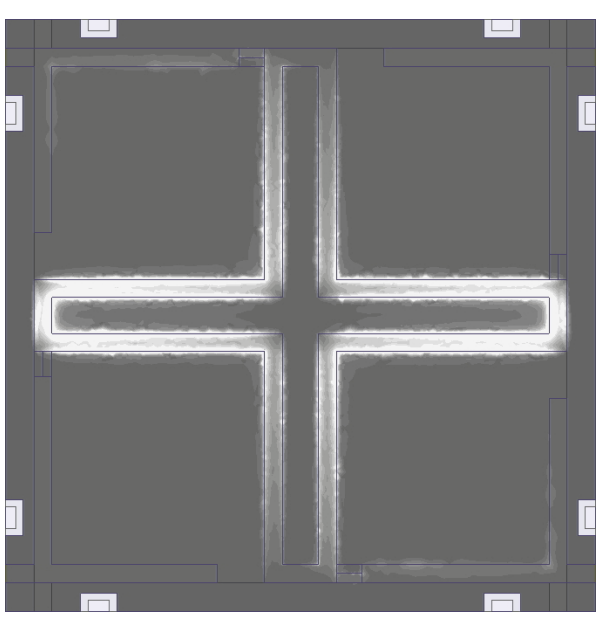

(a)

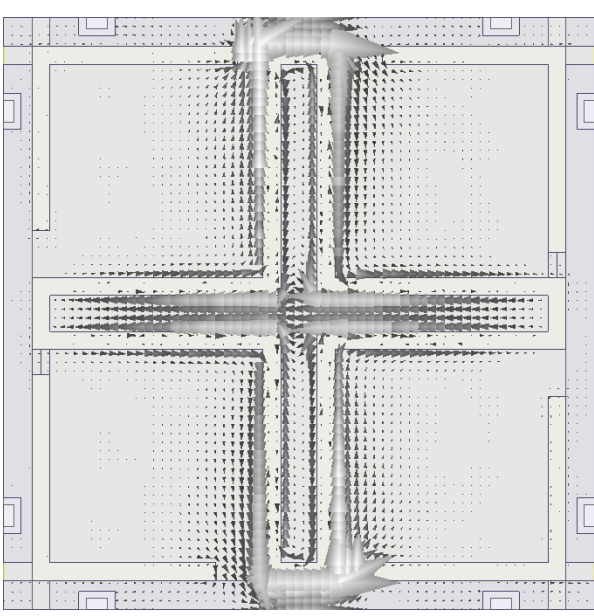

(c)

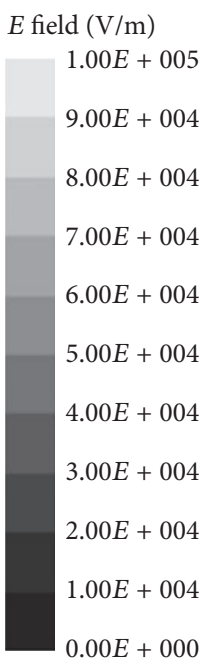

$J \operatorname{surf}(\mathrm{A} / \mathrm{m})$

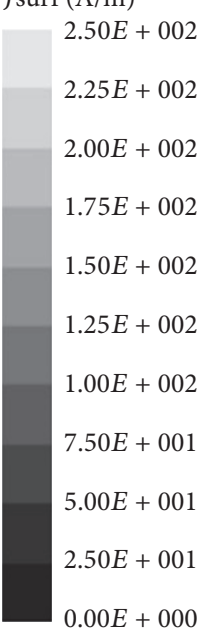

$0.00 E+000$

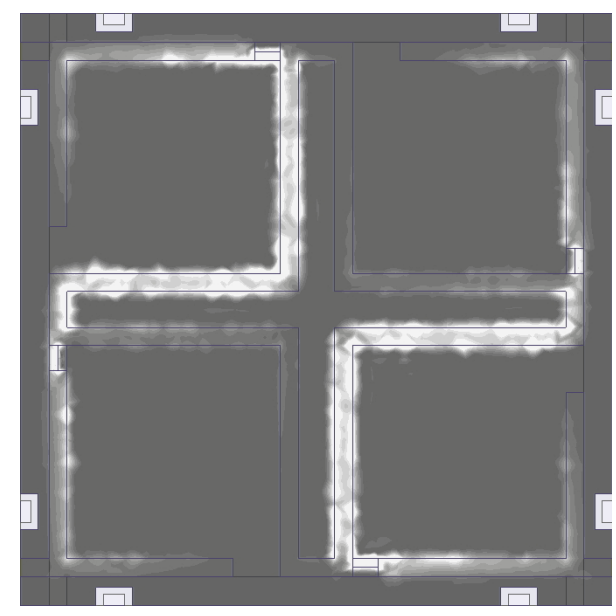

(b)

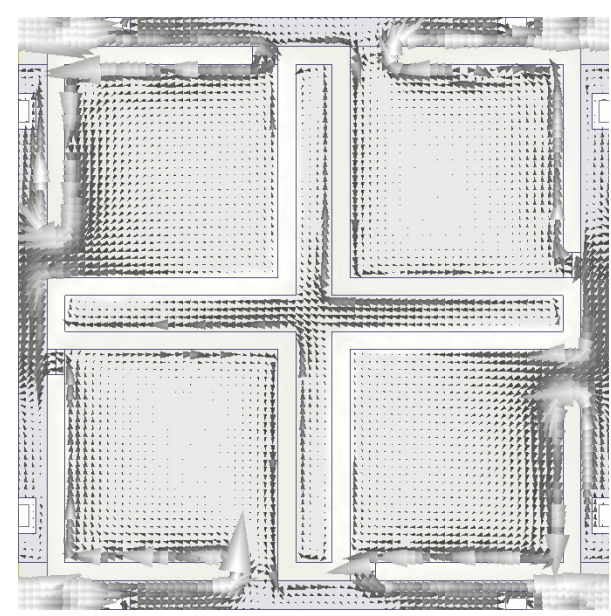

(d)

FIGURE 3: Electromagnetic fields of the proposed AFSS. Electric field in the (a) ON and (b) OFF states; magnetic field in the (c) ON and (d) OFF states.

beamforming, which reconfigures antenna radiation patterns for improved communication [20], and stealth technology in the defense sector by using features such as filtering to selectively reflect and transmit certain frequencies [21]. To employ the proposed AFSS structure, it is critical to ensure its durability and operational stability under various environmental factors, such as dust, temperature, humidity, and mechanical impact. Therefore, the AFSS requires additional supporting structures; hence, we fabricated it in a multifaceted manner with composite materials having mechanical and electronic features that are suitable with the FSS operation. In contrast, previous studies focused only on improving the electronic performance for the dielectric substrate and plane waves and did not address design and performance considering environmental conditions, which imply the analysis of curvature and composite materials.

By considering environmental conditions, we strengthened the AFSS structure with a fiber-reinforced composite, which is light but very strong, and evaluated the effect of the dielectric characteristics and curvature of the composite materials on the AFSS transmission. We used UGN200 Eglass/epoxy produced by SK chemicals as the fiber-reinforced composite and fabricated the structure using a co-cure bonding method. This method does not increase the weight and evenly distributes the load in the area between the adhesively bonded joints. To prevent any alteration of the PIN diode, we metalized it at a temperature below $120^{\circ} \mathrm{C}$ and subsequently applied a foam-core sandwich structure as it slowly cooled down to room temperature [17]. This structure provides an optimized design factor, which minimizes the variation and delamination between the composite material and the FSS structure to reduce the thermal induced residual stress due to the difference in the coefficients of thermal expansion. In addition, we used the 71HF foam produced by ROHACELL as a filler block. To build the composite-based AFSS with a single curvature, we accumulated the multilayered E-glass/epoxy 


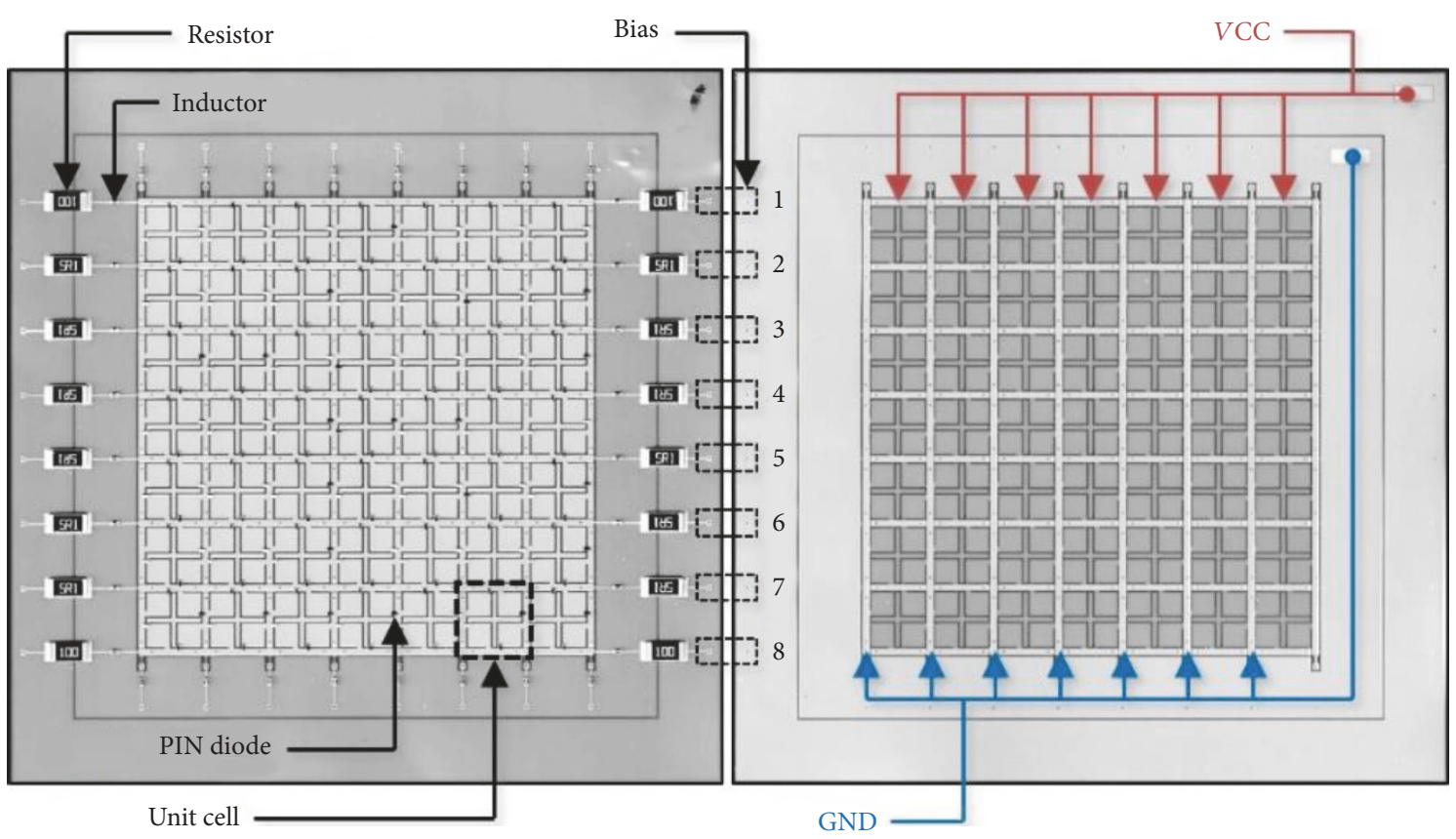

(a) Fabricated AFSS

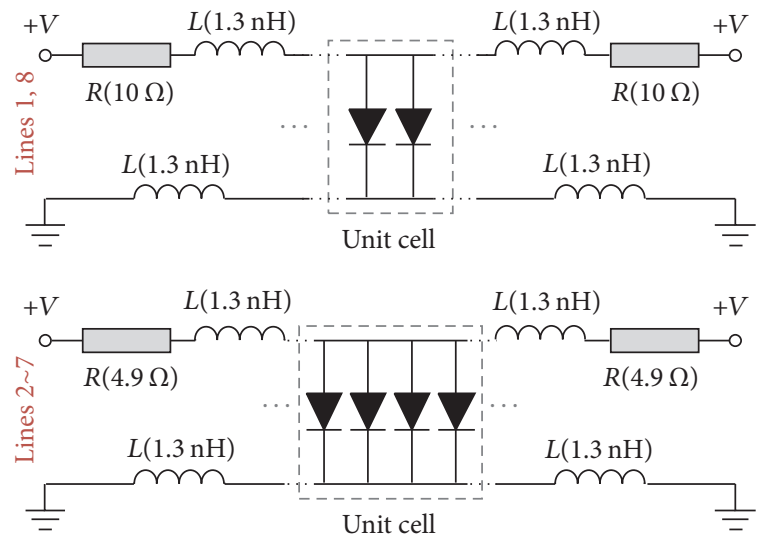

(b) Bias circuit

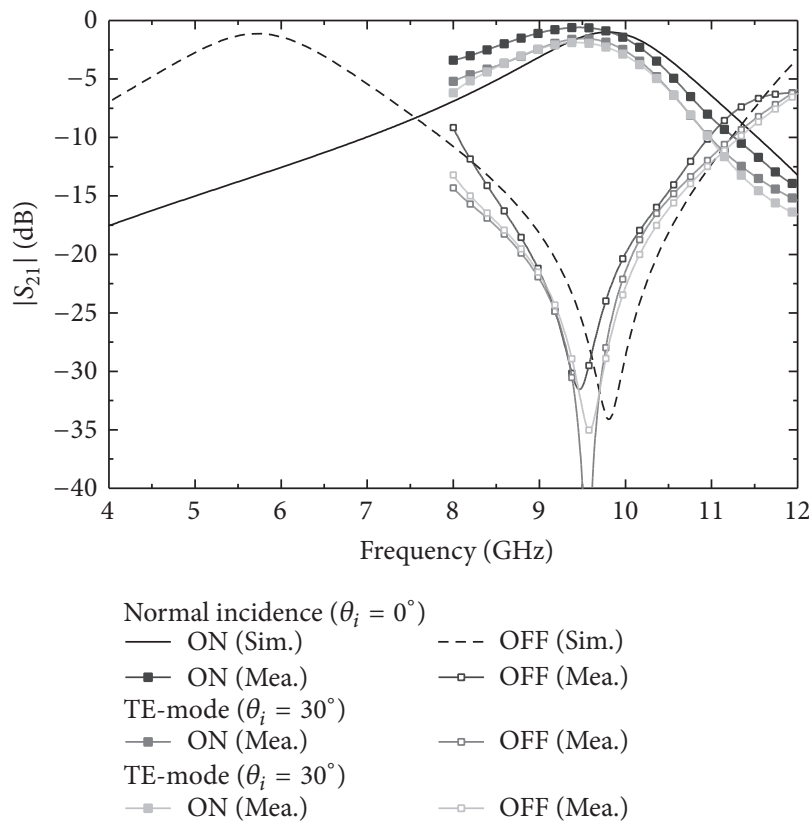

(c) Transmission characteristics (Sim.: simulation, Mea.: measurement)

FIGURE 4: Structure, bias circuit, and operational evaluation of the fabricated AFSS.

prepreg (preimpregnated materials) and a release film by making a curved mold using an autoclave (i.e., minipressure curing oven). As illustrated in Figure 5, we first heated up the entire assembly of the prepreg layup under vacuum in order to melt the resin and remove volatiles. Next, the layup was heated at a higher temperature and under high pressure and then gradually cooled down to minimize residual stresses and prevent microcracking.

The prepreg layup was composed of four E-glass/epoxy composite laminas (skin), with the conditions for the autoclave molding to cure the composite shown in Figure 6(a). After fabricating composite skin, we attached adhesive films on both sides of the foam by applying vertical force to the stacked materials for them to properly bind. Then, we placed the specimen within a vacuum bag to cure the adhesive films using the conditions shown in Figure 6(b) [22]. A unit cell of the proposed AFSS structure is illustrated in Figure 6(c), and the cross section of the complete singlecurvature (radius $R$ of $532 \mathrm{~mm}$ or $100 \mathrm{~mm}$ ) AFSS structure is shown in Figure 6(d). 
TABLE 4: Simulation results and measurements of the proposed AFSS.

\begin{tabular}{|c|c|c|c|c|}
\hline \multirow{2}{*}{ Incident wave } & \multicolumn{3}{|c|}{ ON state } & \multirow{2}{*}{$\begin{array}{c}\text { OFF state } \\
\text { Isolation } f_{\mathrm{ON}}-f_{\mathrm{OFF}}(\mathrm{dB})\end{array}$} \\
\hline & $f_{r}(\mathrm{GHz})$ & $S_{21}(\mathrm{~dB})$ & $-3 \mathrm{~dB}$ BW $(\mathrm{GHz})$ & \\
\hline \multicolumn{5}{|c|}{ AFSS only } \\
\hline Normal & 9.46 & -0.59 & 2.08 & 30.96 \\
\hline $\mathrm{TE} 30^{\circ}$ & 9.51 & -1.54 & 1.27 & 39.50 \\
\hline $\mathrm{TM} 30^{\circ}$ & 9.43 & -1.88 & 1.20 & 28.90 \\
\hline \multicolumn{5}{|c|}{ AFSS with curved composite structure $(R=532 \mathrm{~mm})$} \\
\hline Normal & 9.59 & -0.67 & 2.55 & 17.07 \\
\hline $\mathrm{TE} 30^{\circ}$ & 9.51 & -2.27 & 1.44 & 22.41 \\
\hline \multicolumn{5}{|c|}{ AFSS with curved composite structure $(R=100 \mathrm{~mm})$} \\
\hline Normal & 9.65 & -1.39 & 2.22 & 17.20 \\
\hline TE $30^{\circ}$ & 9.55 & -2.21 & 1.23 & 16.36 \\
\hline
\end{tabular}

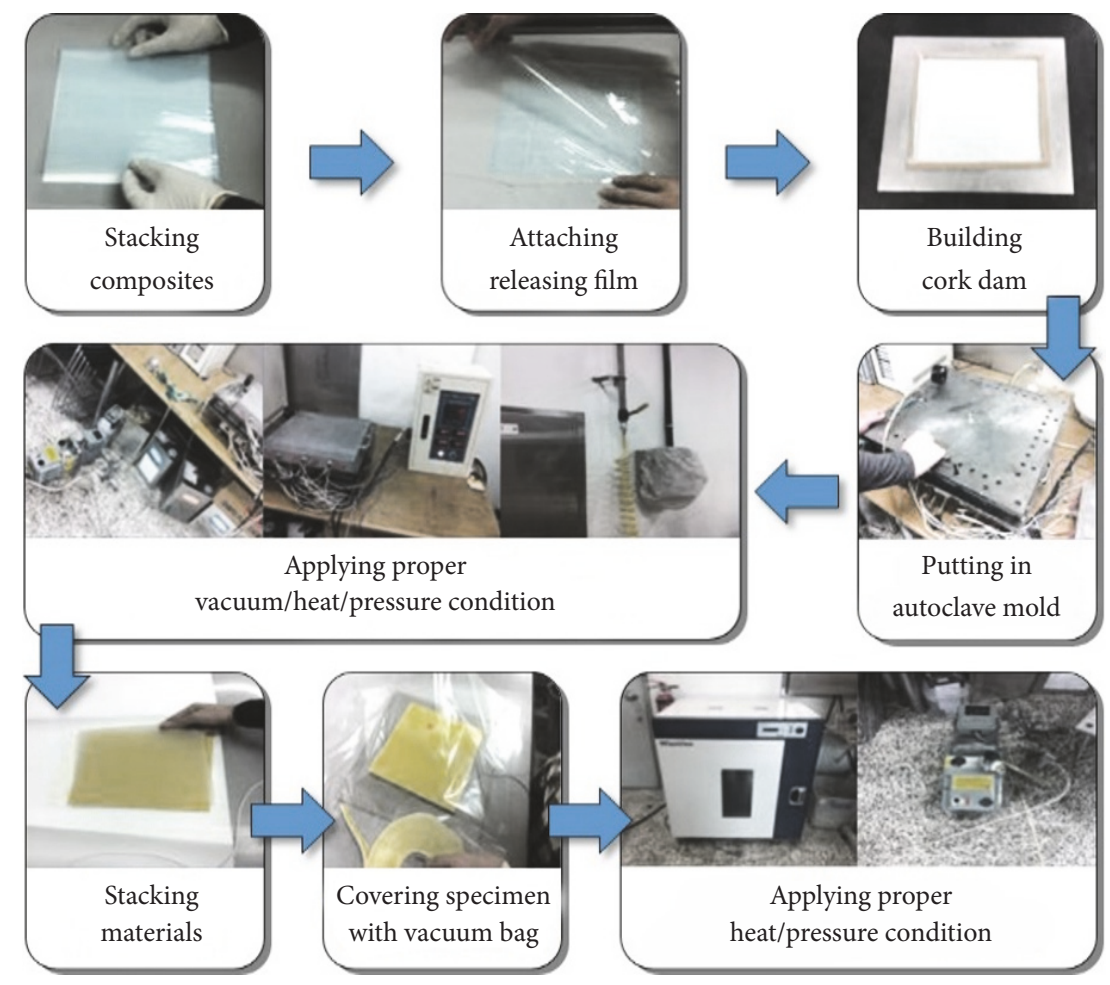

FIgURE 5: Fabrication process of the single-curvature AFSS with composite materials.

Using the free-space method, we evaluated the transmission characteristics of the fabricated AFSS structure for incidence angles of $0^{\circ}$ and $30^{\circ}$ and curves with radii of $532 \mathrm{~mm}$ and $100 \mathrm{~mm}$. The experimental setup is shown in Figure 7(a), and the results are shown in Figures $7(\mathrm{~b})$ and $7(\mathrm{c})$. To obtain simulation results for comparison with the measurements and evaluate the impact of the composite structures and three-dimensional shape on the AFSS transmission, we simulated the curved composite structure using a semifinite model in the normal incidence case (i.e., $0^{\circ}$ incidence angle), as shown in Figure 7(b) [23]. Moreover, in order to confirm the measurement error due to the finite effects by a small number of arrays, we observed the transmission characteristics of the proposed FSS (without PIN diode) and curved composite structure (without FSS), which have the same size of the proposed structure.

Table 4 lists the transmission characteristics depending on the incidence angle and curve radius when the PIN diode is in the $\mathrm{ON}$ and $\mathrm{OFF}$ states. The plane wave with a $0^{\circ}$ incidence angle shows a resonance frequency variation below $0.63 \%$ and a maximum transmission loss of $-1.39 \mathrm{~dB}$, whereas the plane wave with a $30^{\circ}$ incidence angle shows a resonance frequency variation of up to $1.47 \%$ and a maximum transmission loss of $-2.27 \mathrm{~dB}$, which depends on the curvature. In addition, given the dielectric features of the composite material, the bandwidth and transmission loss in the $\mathrm{ON}$ 


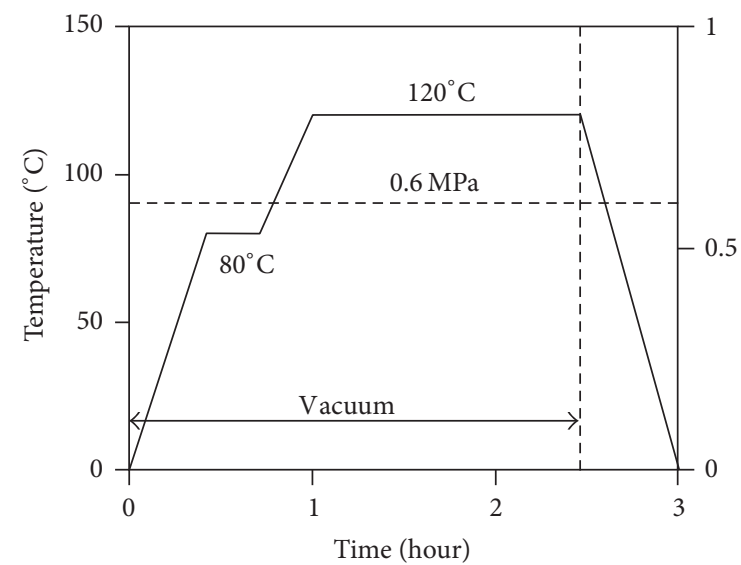

(a) Curing process of E-glass/epoxy composite

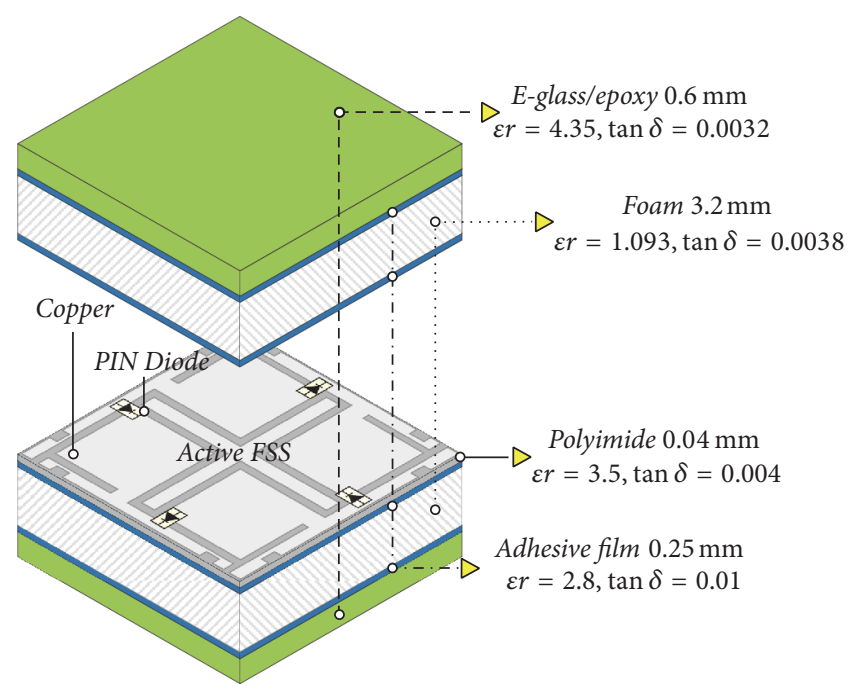

(c) Composite structures including AFSS

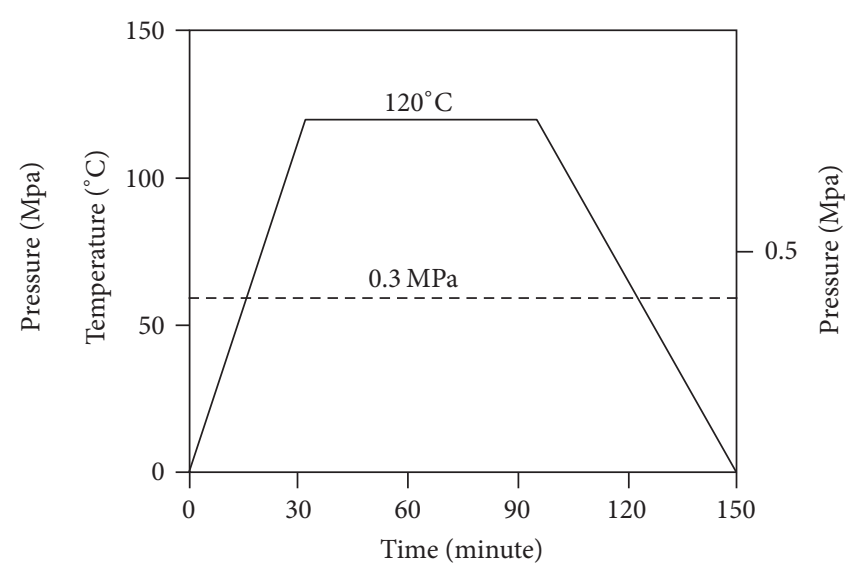

(b) Curing process of adhesive film

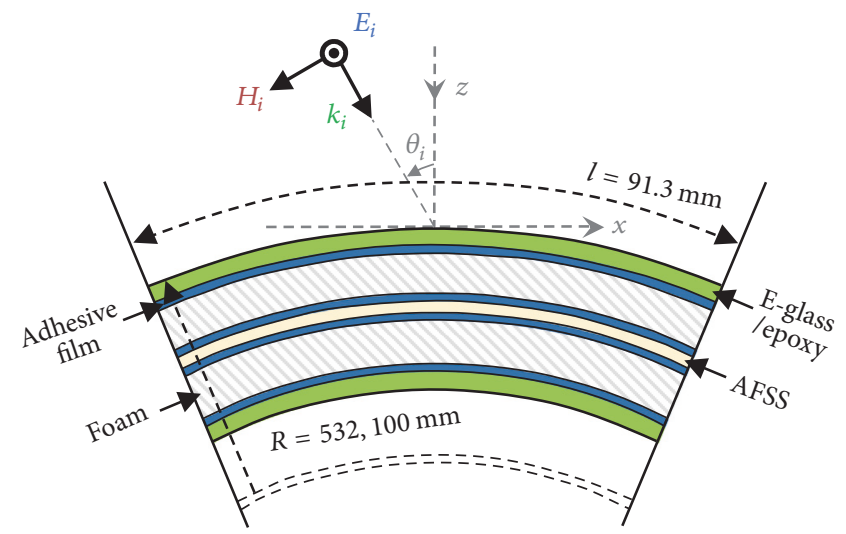

(d) Cross section of the complete AFSS structure

FIGURE 6: Design and fabrication specifications of the single-curvature AFSS with composite materials.

state tend to increase when only using the AFSS. In contrast, the bandwidth decreases and the transmission loss increases when using the curved AFSS. From the measurements, we confirmed that the bandwidth and transmission loss of the passband in the ON state increased by the dielectric properties of the composite material. Furthermore, we found that the transmission loss increased and the bandwidth decreased with an increasing curvature. The increase in transmission loss might be due to the change in the composite material properties, such as an increase in the effective permittivity and dielectric loss [24]. The bandwidth narrowing might be due to a weak mutual coupling among the unit cells as the phase difference of their magnetic field in the curved surface increases with respect to the incident plane wave $[25,26]$.

Overall, we found that the proposed curved AFSS structure with composite materials has a lower performance in terms of transmission and reflection than the single AFSS structure, as the former has a lower isolation between operating frequencies. However, we verified an acceptable stability and performance with an isolation over $20 \mathrm{~dB}$ regarding the incidence angle and curvature.

\section{Conclusion}

We designed an AFSS structure that can operate in the C-and $\mathrm{X}$-bands and has a flexible substrate. Moreover, we verified its performance when using composite materials to form a single-curvature structure with radius of either $532 \mathrm{~mm}$ or $100 \mathrm{~mm}$ and analyzed the frequency response for each curvature. The proposed structure successfully overcame some limitations of related studies by improving the isolation of the unit cells through a grid-type ON/OFF bias circuit and a via hole and providing a stable frequency response with respect to the angle of incident and polarized waves. From the proposed composite-based AFSS structure, we determined a resonance frequency variation and maximum transmission loss below $1.47 \%$ and $-2.27 \mathrm{~dB}$, respectively, and found that the reconfigured operating frequencies have 


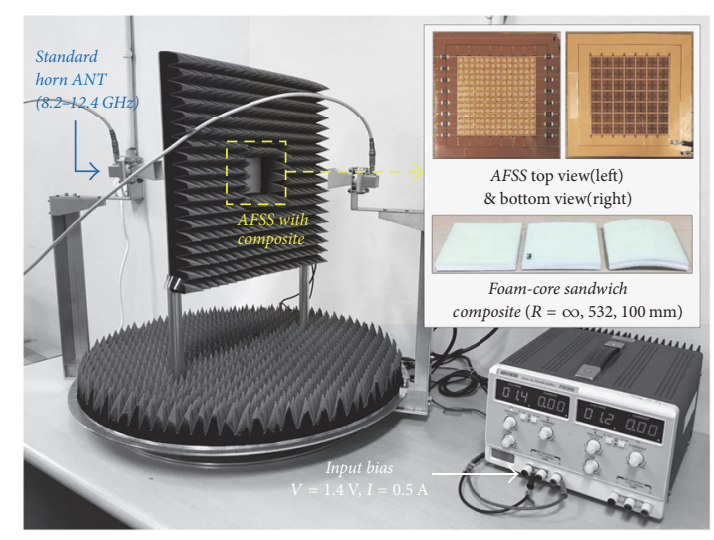

(a) Experimental setup

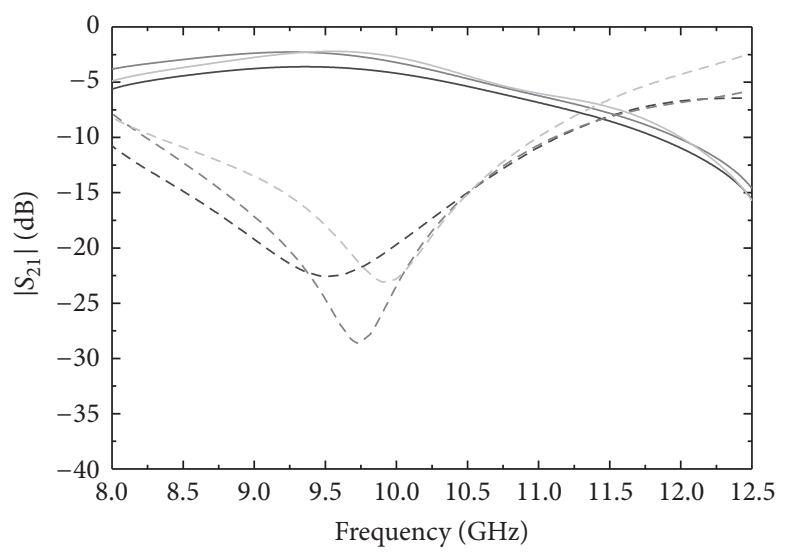

Measurement $\left(\theta_{i}=30^{\circ}\right)$
$R=$ infinite - ON
$R=532 \mathrm{~mm}-$ ON
$R=100 \mathrm{~mm}$ ON - OFF

(c) Transmission under oblique incidence $\left(30^{\circ}\right)$

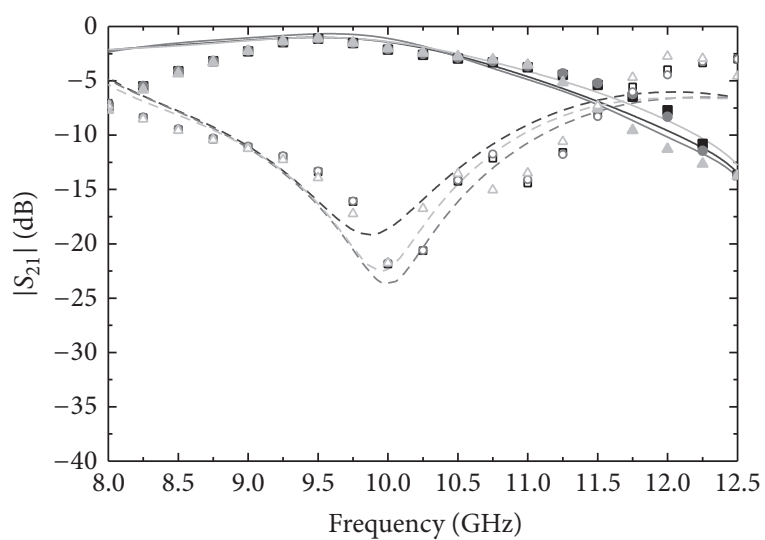

$\begin{array}{ll}\text { Simulation }\left(\theta_{i}=0^{\circ}\right) & \\ R=\text { infinite } \because \text { ON } & \square \text { OFF } \\ R=532 \mathrm{~mm} \bullet \text { ON } & \circ \text { OFF } \\ R=100 \mathrm{~mm} \triangle \mathrm{ON} & \triangle \text { OFF } \\ \text { Measurement }\left(\theta_{i}=0^{\circ}\right) & \\ R=\text { infinite }- \text { ON } & -- \text { OFF } \\ R=532 \mathrm{~mm}-\text { ON } & -- \text { OFF } \\ R=100 \mathrm{~mm}-\text { ON } & -- \text { OFF }\end{array}$

(b) Transmission under normal incidence $\left(0^{\circ}\right)$

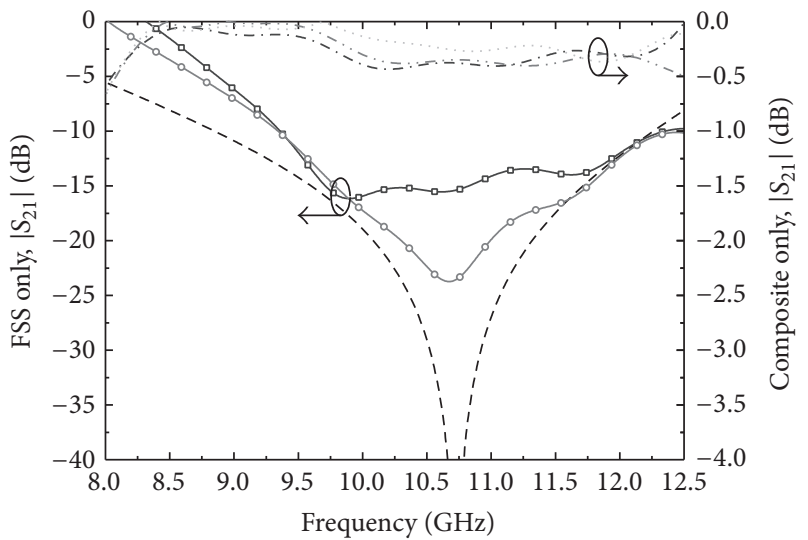

$$
\begin{aligned}
& \text { Composite w/o FSS } \\
& -\cdots R=\text { infinite } \\
& -\cdots-R=532 \mathrm{~mm} \\
& \text { FSS w/o PIN diode }(R=\text { infinite }) \\
& --- \text { Infinite FSS (Sim.) } \\
& -\square \text { Finite } 5 \times 5 \text { FSS (Mea.) } \\
& -\square \text { Finite } 7 \times 7 \text { FSS (Mea.) }
\end{aligned}
$$

(d) Finite effects at the normal incidence

FIGURE 7: Fabricated AFSS and measured transmission characteristics.

less isolation. In other words, compared to previous studies, the proposed structure provides a stable performance and improved isolation over $20 \mathrm{~dB}$, in terms of the structure curvature and incidence angle, even when the performance of the composite-based AFSS structure is inferior to that of the single AFSS structure.

This study showed that more research considering multidimensional shapes and composite materials is needed to apply such structures in real environments guaranteeing stability. Hence, our upcoming research plans include the application of FSS in a real working environment and the consideration of other mechanical factors affecting its frequency response.

\section{Conflicts of Interest}

The authors declare that there are no conflicts of interest regarding the publication of this paper. 


\section{Acknowledgments}

This work has been supported by the Low Observable Technology Research Center program of Defense Acquisition Program Administration and Agency for Defense Development.

\section{References}

[1] B. A. Munk, Frequency Selective Surface: Theory and Design, John Wiley \& Sons, 2005.

[2] M. Yan, S. Qu, J. Wang et al., "A miniaturized dual-band FSS with stable resonance frequencies of $2.4 \mathrm{GHz} / 5 \mathrm{GHz}$ for WLAN applications," IEEE Antennas and Wireless Propagation Letters, vol. 13, pp. 895-898, 2014.

[3] C. Sudhendra, A. R. Madhu, A. C. R. Pillai, R. Kark, and T. S. Rukmini, "A novel ultra wide band radar absorber based on hexagonal resistive patch FSS," in Proceedings of the 4th IEEE Applied Electromagnetics Conference, AEMC 2013, pp. 1-2, December 2013.

[4] S. V. Hum and J. Perruisseau-Carrier, "Reconfigurable reflectarrays and array lenses for dynamic antenna beam control: a review," IEEE Transactions on Antennas and Propagation, vol. 62, no. 1, pp. 183-198, 2014.

[5] J. P. Turpin, J. A. Bossard, K. L. Morgan, D. H. Werner, and P. L. Werner, "Reconfigurable and tunable metamaterials: a review of the theory and applications," International Journal of Antennas and Propagation, vol. 2014, Article ID 429837, 18 pages, 2014.

[6] M. Safari, C. Shafai, and L. Shafai, "X-band tunable frequency selective surface using MEMS capacitive loads," Institute of Electrical and Electronics Engineers. Transactions on Antennas and Propagation, vol. 63, no. 3, pp. 1014-1021, 2015.

[7] B. Sanz-Izquierdo, E. A. Parker, and J. C. Batchelor, "Dual-band tunable screen using complementary split ring resonators," IEEE Transactions on Antennas and Propagation, vol. 58, no. 11, pp. 3761-3765, 2010.

[8] F. Bayatpur and K. Sarabandi, "Design and analysis of a tunable miniaturized-element frequency-selective surface without bias network," IEEE Transactions on Antennas and Propagation, vol. 58, no. 4, pp. 1214-1219, 2010.

[9] M. M. Masud, B. Ijaz, A. Iftikhar, M. N. Rafiq, and B. D. Braaten, "A reconfigurable dual-band metasurface for EMI shielding of specific electromagnetic wave components," in Proceedings of the 2013 IEEE International Symposium on Electromagnetic Compatibility, EMC 2013, pp. 640-644, August 2013.

[10] K. Qi, X. Yuan, and Y. Wang, "A tunable microwave absorber based on active frequency selective surface," in Proceedings of the Progress in Electromagnetics Research Symposium, PIERS 2014, pp. 791-793, August 2014.

[11] P. Kong, X. W. Yu, M. Y. Zhao, Y. He, L. Miao, and J. J. Jiang, "Switchable frequency selective surfaces absorber/reflector for wideband applications," Journal of Electromagnetic Waves and Applications, vol. 29, no. 11, pp. 1473-1485, 2015.

[12] J. Li, J. Jiang, Y. He et al., "Design of a tunable low-frequency and broadband radar absorber based on active frequency selective surface," IEEE Antennas and Wireless Propagation Letters, vol. 15, pp. 774-777, 2016.

[13] H. Wang, P. Kong, W. Cheng et al., "Broadband tunability of polarization-insensitive absorber based on frequency selective surface," Scientific Reports, vol. 6, Article ID 23081, 2016.

[14] H. Zhou, S. Qu, B. Lin et al., "Filter-antenna consisting of conical FSS radome and monopole antenna," IEEE Transactions on Antennas and Propagation, vol. 60, no. 6, pp. 3040-3045, 2012.

[15] I. Choi, D. Lee, and D. G. Lee, "Hybrid composite lowobservable radome composed of E-glass/aramid/epoxy composite sandwich construction and frequency selective surface," Composite Structures, vol. 117, no. 1, pp. 98-104, 2014.

[16] N. Khatavkar and K. Balasubramanian, "Composite materials for supersonic aircraft radomes with ameliorated radio frequency transmission-a review," RSC Advances, vol. 6, no. 8, pp. 6709-6718, 2016.

[17] I.-H. Hwang, H.-J. Chun, I.-P. Hong, Y.-B. Park, and Y.J. Kim, "Change of transmission characteristics of FSSs in hybrid composites due to residual stresses," Steel and Composite Structures, vol. 19, no. 6, pp. 1501-1510, 2015.

[18] I.-G. Lee, Y.-J. Kim, Y.-B. Park, H.-J. Chun, and I.-P. Hong, "Design of X-band reconfigurable frequency selective surface with high isolation," IEICE Electronics Express, vol. 13, no. 16, pp. 1-8, 2016.

[19] F.-C. Huang, C.-N. Chiu, T.-L. Wu, and Y.-P. Chiou, "A circularring miniaturized-element metasurface with many good features for frequency selective shielding applications," IEEE Transactions on Electromagnetic Compatibility, vol. 57, no. 3, pp. 365-374, 2015.

[20] S. M. Mahmood and T. A. Denidni, "Pattern-reconfigurable antenna using a switchable frequency selective surface with improved bandwidth," IEEE Antennas and Wireless Propagation Letters, vol. 15, pp. 1148-1151, 2016.

[21] F. Costa and A. Monorchio, "A frequency selective radome with wideband absorbing properties," Institute of Electrical and Electronics Engineers. Transactions on Antennas and Propagation, vol. 60, no. 6, pp. 2740-2747, 2012.

[22] Y. S. Seo, Study of the Fabrication of Hybrid Composite Plate with Active Frequency Selective Surface, Department of Mechanical Engineering at Yonsei University, Seoul, Korea, 2014.

[23] A. Dalkilic, L. Alatan, and C. B. Top, "Analysis of conformal frequency selective surface radome," in Proceedings of the 8th European Conference on Antennas and Propagation (EuCAP'14), pp. 469-472, The Hague, Netherlands, April 2014.

[24] P. Callaghan, E. A. Parker, and R. J. Langley, "Influence of supporting dielectric layers on the transmission properties of frequency selective surfaces," IEE Proceedings Part H Microwaves, Antennas and Propagation, vol. 138, no. 5, pp. 448-454, 1991.

[25] S. Savia and E. A. Parker, "Current distribution across curved ring element FSS," in Proceedings of the IEE National Conference on Antennas and Propagation, pp. 332-335, York, UK, 1999.

[26] P. Samaddar, S. Sarkar, S. De, S. Biswas, D. C. Sarkar, and P. P. Sarkar, "Bandpass planer and hemispherical fss comprising of tripole element," International Journal of Physical Sciences, vol. 18, pp. 14-18, 2014. 


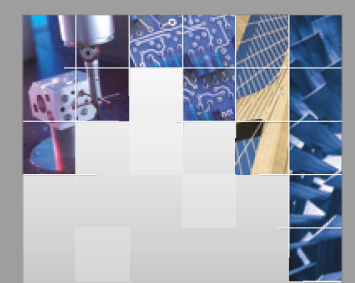

\section{Enfincering}
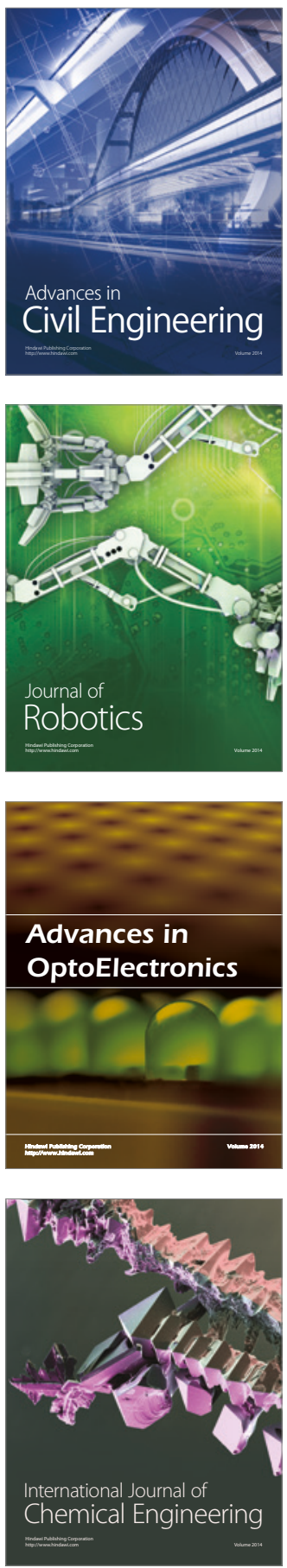

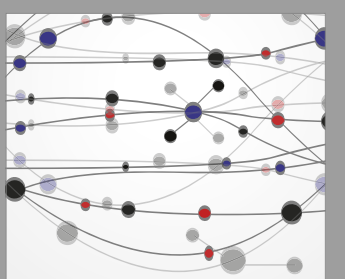

The Scientific World Journal

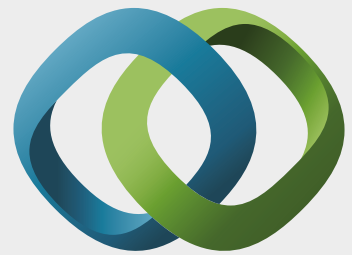

\section{Hindawi}

Submit your manuscripts at

https://www.hindawi.com
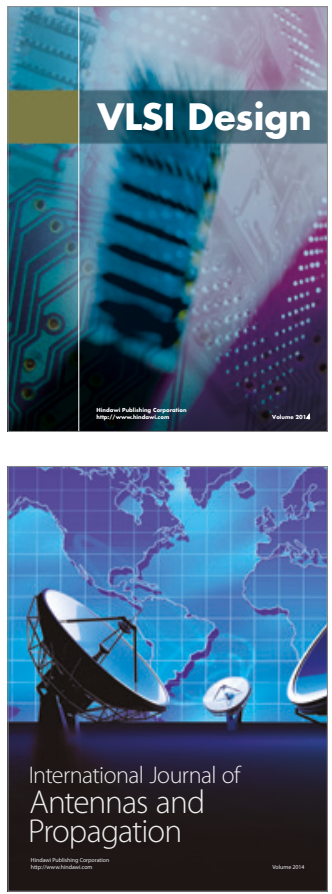

\section{Rotating}

Machinery
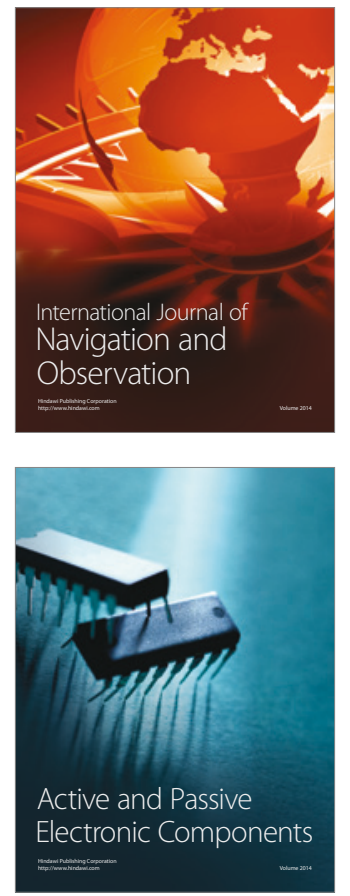
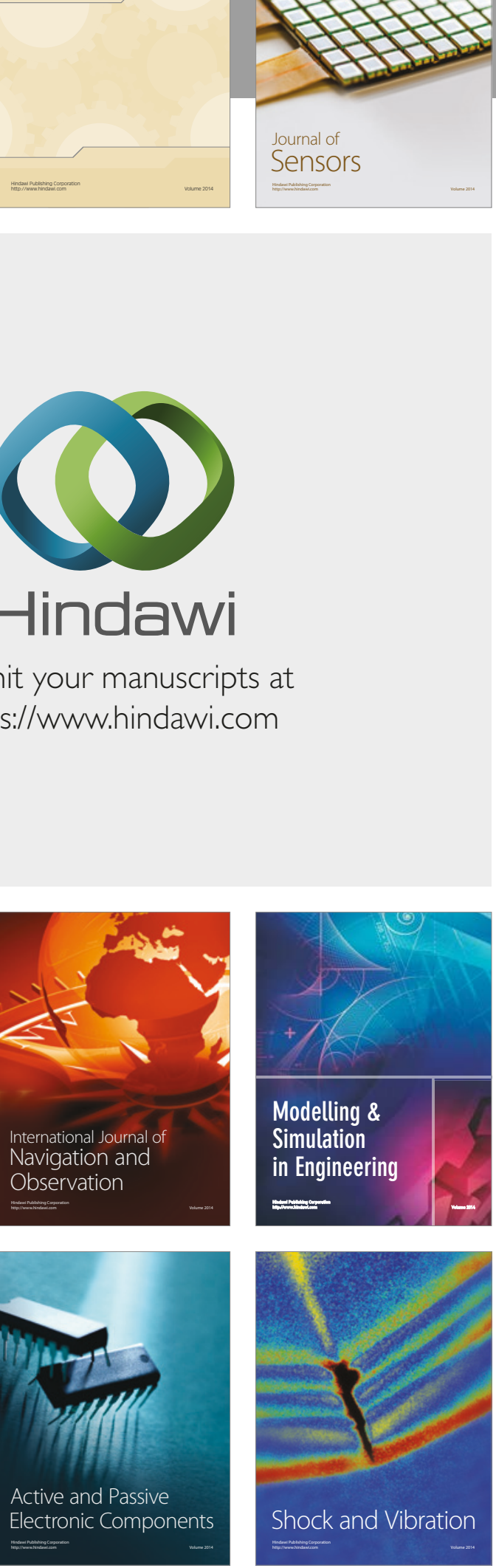
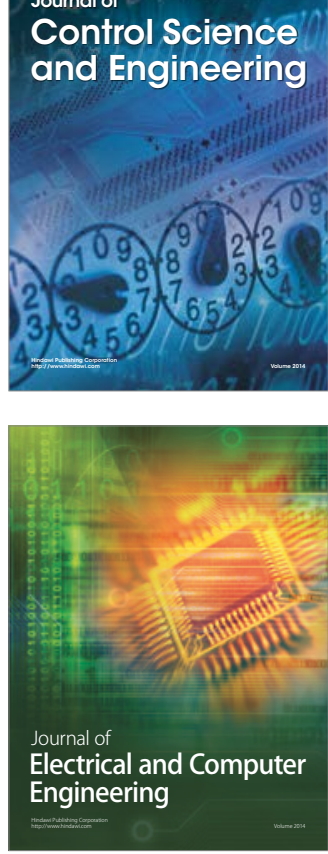

Distributed

Journal of

Control Science

and Engineering
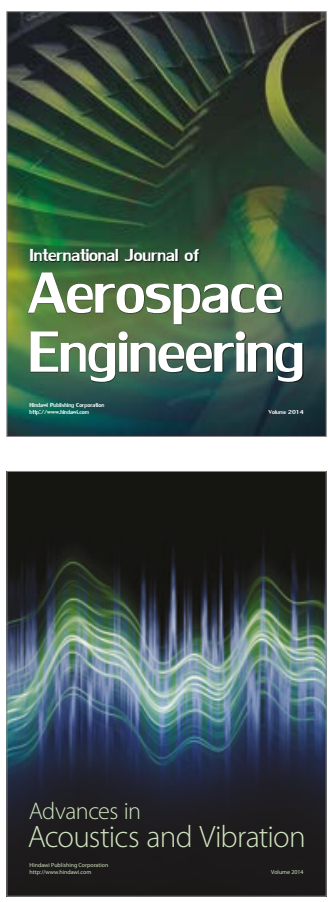

Sensor Networks 